\title{
Decision support system for bankruptcy risk assessment of the enterprise
}

\author{
Elena Viktorovna Telipenko \\ Yurga Institute of Technology, Tomsk Polytechnic \\ University affiliate \\ Yurga, Russia \\ KochetkovaEV@mail.ru
}

\author{
Alexandra Alexandrovna Zakharova, Svetlana Petrovna \\ Sopova, Sergey Leonidovich Min'kov, Nurbek \\ Bakytbekovich Dzhamansariev \\ Yurga Institute of Technology, Tomsk Polytechnic \\ University affiliate \\ Yurga, Russia \\ Tomsk State University, \\ Tomsk, Russia \\ KochetkovaEV@mail.ru
}

\begin{abstract}
Often it is not enough to get only a quantitative assessment when evaluating the current financial status of the enterprise and identifying its bankruptcy risk level. It is important to know how each index involved into bankruptcy risk assessment varies from standard and how the risk level can change if a value of one or several indexes change. The paper represents a description and scheme of work with an intellectual information system for bankruptcy risk assessment of the enterprise (IISBRAE), which can help a decision maker answer these questions and make a timely management decision.
\end{abstract}

Keywords - bankruptcy risk assessment, intellectual information system, connectionist model

\section{INTRODUCTION}

IISBRAE has been developed within the framework of the project of the Russian Foundation for Basic Research №1401-31208. The system uses a connectionist model as a mathematical base for bankruptcy risk assessment of the enterprise.

\section{SCHEME OF WORK WITH IISBRAE}

Picture 1 shows the scheme of work with IISBRAE. The process of work the system can be figuratively divided into five main stages.

Stage 1. When running a program one can see the main program window at the top of which there is the main menu with five sections: file, data input, neural network, data analysis, and information.

User's work with the program starts either with assessment of an enterprise current state or with system database operation, i.e. database population and correction of existing data. To do this it is necessary to go to "Data Input".

Loading of new date into the base MySQL can be done by two ways: by loading .xls files with accounting reports, and by inputting data by hands.

IISBRAE database has a training set with accounting report data on the basis of which the program calculates values of 10 most impotent (qualitative) indexes for bankruptcy risk assessment of the enterprise. These indexes are: $\mathrm{x} 1$ - working capital ratio, $\mathrm{x} 2$ - acid test ratio, $\mathrm{x} 3$ - absolute liquidity ratio, $\mathrm{x} 4$ - liquid capital ratio in assets, $\mathrm{x} 5$ - concentration ratio of capital loans, $\mathrm{x} 6$ - long term fund raising ratio, $\mathrm{x} 7$ - borrowed and own funds ratio, x 8 - turn-round of float, $\mathrm{x} 9$ - turn-round of owned capital, x10 - product profitability [1].

Reliability of this index system is proved by a research described in the thesis "Decision support system for enterprise bankruptcy risk management" [2].

However the proposed quantitative index system was added by one more qualitative index, which influences the bankruptcy risk level. It is x11 - form of incorporation (JSC, CJSC, and LLC).

Importance of this index for bankruptcy risk assessment was examined by the correlation analysis. To prove dependency of the index "form of incorporation" from bankruptcy risks E.V. Telipenko constructed a deployment diagram. The diagram shows that enterprises with CJSC incorporation form have less bankruptcy risks. The most enterprises in default have LLC incorporation form.

Then the authors selected companies with accurate financial reporting on the basis of which the authors calculated 11 mentioned indexes. To make the research the authors chose manufacturing enterprises with OKVD 29 - Machinery and equipment production, excluding OKVD 29.6 - Arms and weapon production [3].

It is also possible to correct already inputted data if it is necessary.

The process of index value calculation used for bankruptcy risk level assessment is hidden from users.

To calculate values of mentioned indexes two program modules are realized in Delphi XE3: the first module is responsible for scarping, the second module is in charge of data pre-processing - normalization and index value calculations. There is a special database on My SQL Server 5.3 for keeping calculated index values [4]. 


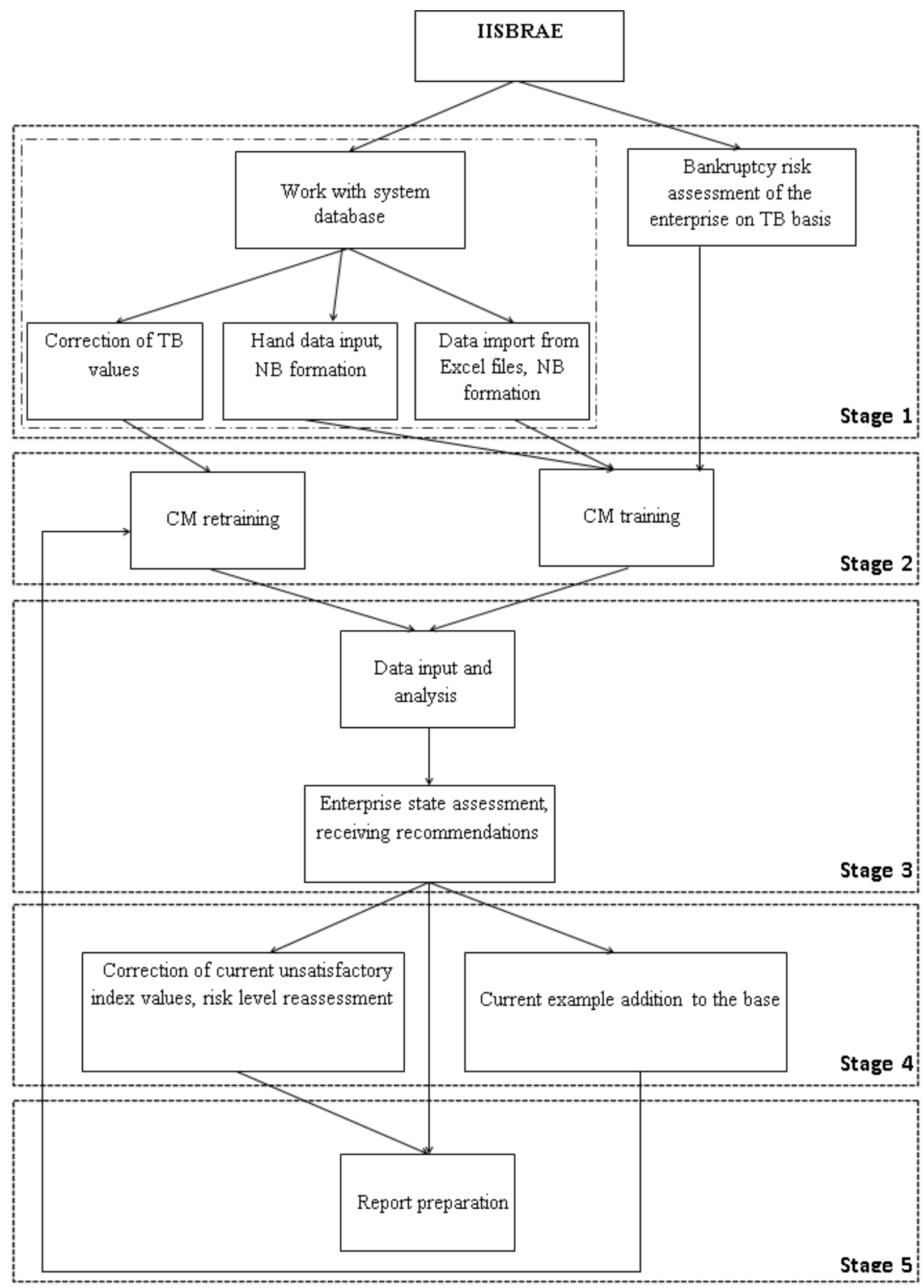

Fig. 1. Scheme of work with IISBRAE 
When data is loaded and index values are calculated the process of data pre-processing with the help of models on the basis of fuzzy logic takes place.

The authors have constructed a membership function for each index. On the basis of this function the authors classify index values and rank them among this or that level (low, average, high). Index resultant into one integrated bankruptcy risk level is calculated according to the formula:

$$
\mathrm{g}=\sum_{\mathrm{j}=1}^{3} \mathrm{~g}_{\mathrm{j}} \sum_{i=1}^{N} \mathrm{r}_{i} \times \lambda_{\mathrm{ij}}
$$

where $g_{\mathrm{i}}=0.9-0.4 \times(j-1)$ is a multiplier for a basic three-layer fuzzy 01 -qualifier,

$\lambda_{i j}$ - the result of index value classification according to sub-collections (low, average, high) [5].

Classification of $\mathrm{g}$ risk level is realized on the basis of the following table [2]:

\section{TABLE I. CLASSIFICATION OF A RISK LEVEL INDEX}

\begin{tabular}{|l|c|l|}
\hline \multicolumn{1}{|c|}{ Limits for $g$} & $\begin{array}{c}\text { Risk level } \\
\text { classification }\end{array}$ & \multicolumn{1}{|c|}{$\begin{array}{c}\text { Evaluating reliance } \\
\text { level }\end{array}$} \\
\hline $0<=\mathrm{g}<=0.2$ & Low & 1 \\
\hline \multirow{2}{*}{$0.2<\mathrm{g}<0.4$} & Low & $\mu 1=5^{*}(0.4-\mathrm{g})$ \\
\cline { 2 - 3 } & Viable & $1-\mu 1=\mu 2$ \\
\hline $0.4<=\mathrm{g}<=0.6$ & Viable & 1 \\
\hline \multirow{2}{*}{$0.6<\mathrm{g}<0.8$} & Viable & $\mu 2=5^{*}(0.8-\mathrm{g})$ \\
\cline { 2 - 3 } & High & $1-\mu 2=\mu 3$ \\
\hline $0.8<=\mathrm{g}<=1.0$ & High & 1 \\
\hline
\end{tabular}

This stage is for preliminary evaluation of bankruptcy risk level. The obtained result is not a binary assessment $(0-$ financially stable enterprise, 1 - indicator, enterprise is a bankrupt), it is a smarter continuous evaluation (from 0 to 1 ), which shows how low or high the risk level is.

Usage of such data output for training allows users to have a more nuanced connectionist model. In the end it gives the most exact outcome with information about bankruptcy risk assessment.

Stage 2. The second stage is for either connectionist model training, or retraining depending on the previous action: inserting of new data or its correction.

Creation of network configuration and its training is done with the help of the program Deductor Studio.

Input data values are calculated - 11 indexes on the basis of annual accounting reports for 2011-2013. It gives 347 training examples (irregular units of observation are out of the collection).
There is only one output signal, it is bankruptcy. Variable values are a continuous quantity referred to the interval [0:1].

Choice of appropriate amount of processing elements is made with the help of Arnold-Kolmogorov-Khekht-Nilson theorem. The appropriate processing element amount on a hidden layer is 40 .

When projecting and training the network the following parameters have been used:

- Training algorithm - back propagation of error.

- Significance initialization - automatically.

- $\quad$ Number of input factors -11 .

- Number of output factors -1 .

- Number of processing elements on a hidden layer -

40.

- $\quad$ Number of training examples - 347.

- $\quad$ Training set $-95 \%$ (330 lines).

- $\quad$ Testing set - 5\% (17 lines).

- Activation function type - sigmoid function.

- $\quad$ Learning curve -1 .

- Acceptable error level (a stoppage condition) - 0,05.

- Average error for a training set -0,02 (2\%).

- $\quad$ Average error for a testing set - 0,053 (5,3\%).

- Training time - 6 min 09 sec.

- Number of training stages - 23154 .

- Taken into account from a training set $-97,65 \%$.

- Taken into account from a testing set $-93,34 \%$.

Training network process can take several minutes. It depends on user's computer special features. At this, the user sees on the screen the following message: "Please, wait. Neural network training is on process". When the training is done, the user sees the following message: "Neural network training is done".

Stage 3. The user can open the main program division "Data Analysis" right after running a program if he/she does not want to enter new data into the database and make an analysis on the basis of available data and the connectionist model. To make an analysis of enterprise financial stability it is necessary to enter the data with accounting reports for a certain period and click the button "Analyse".

Then the user can see a window with the results of the analysis. At the top of the window one can see an assessment value of bankruptcy risk level and below there is its linguistic interpretation according to the Table $1[7,8]$.

In the bottom part of the window there are calculated index values and information about deviation of these values from average ones in the field (in \%). Average values are given in brackets. The user also receives a recommendation to increase or decrease index values.

Stage 4. If the analysis has been done and the user receives an unsatisfactory value of bankruptcy risk level he/she can simulate index value change and learn how it influences the situation (if there are any improvements). To do this it is 
necessary to enter a new value into the box with an unsatisfactory index and click the button "Calculate". At this, the program calculates bankruptcy risk level and show a new result on the screen.

If it is necessary a new example can be added to the base in order to enlarge it. To do this it is necessary to click the button "Add the example to the base". At this, it is necessary to enter an enterprise name and covered period.

When all necessary data is inputted the program shows a message about the necessity to retrain the network.

If the user agrees to retrain the network the program initiates a corresponding process, which is accompanied by the messages described above.

Stage 5. The obtained results of data analysis can be saved as .xls files.

To assist work with the program there exist a user's operating manual, which is in the menu division "Reference".

To finish working with the program it is necessary to click "File" in the menu and choose the option "Quit". The program will request confirmation of the action and when it is accepted the program will be closed.

\section{Summary}

The created information system aims to assess enterprise bankruptcy risks and could be applied by enterprise owners, administration bodies, specialists from audit companies to assess current financial status of an enterprise and make decisions for changing the situation if a risk assessment is unsatisfactory.

The program implements the following functions:

- calculation of key index values crucial for bankruptcy risk assessment;

- calculation of bankruptcy risk generalized assessment on the basis of the connectionist model with the help of possibility theory means;

- $\quad$ analysis of an obtained assessment and making recommendations; possibility to simulate a value change of one or several indexes to influence the situation.

The reported study was funded by RFBR according to the research project № 14-01-31208 mol_a.

\section{REFERENCES}

[1] Telipenko E.V., Chernysheva T.Y., Zakharova A.A., Dumchev A.I. Results of research on development of an intellectual information system of bankruptcy risk assessment of the enterprise // IOP Conference Series: Materials Science and Engineering. - 2015 - Vol. 93 - №. 1, Article number 012058.

[2] Telipenko E.V. Decision support system for enterprise bankruptcy risk management // Thesis for PhD in Technology: 05.13.10 / Siberian State University of Telecommunications and Information Sciences. Novosibirsk, 2013.

[3] Telipenko E.V. Development of an information system for bankruptcy risk assessment of the enterprise on the basis of synthesis of fuzzy logic and connectionist technologies [digital resource]/ E.V. Telipenko// Modern technologies for decision support in economics: Proceedings of the second Russian research/practice conference of undergraduates, postgraduates and young researchers; 19-20 November, 2015, Yurga city/ National Research Tomsk Polytechnic University (TPU), Yurga Institute of technology (YuIT); under the editorship of D.A. Chinakhov. - Tomsk: Publishing house: TPU, 2015. [Pp. 324-325].

[4] Telipenko E.V. Bankruptcy risk assessment of the enterprise on the basis of synthesis of fuzzy logic and connectionist technologies // Proceedings of International research/practice conference "Innovation processes in Russia and in the World", Pp. 98-102.

[5] Telipenko E.V., Zakharova A.A. , Sopova S. P. Forecasting risk of bankruptcy for machine-building plants // IOP Conference Series: Materials Science and Engineering. - 2015 - Vol. 91, Article number 012066.

[6] Telipenko E.V., Zakharova A. A. Bankruptcy risk management of a machine builder // Applied Mechanics and Materials. - 2014 - Vol. 682. - p. 617-622.

[7] Chernysheva T.Y. Preliminary risk assessment in it projects // Applied Mechanics and Materials. - 2013 - Vol. 379. - p. 220-223.

[8] Maslov A. V. Model for Determining the Competitiveness of Science Engineering Products // 7th International Forum on Strategic Technology (IFOST - 2012): Proceedings: in 2 vol., Tomsk, September 18-21, 2012. - Tomsk: TPU Press, 2012 - Vol. 1 - p. 511- 514. 